\title{
The lessons of Africa's industrial 'failure'
}

\author{
Manfred Bienefeld
}

A quarter century after the decolonisation of Africa, the dreams of those who struggled for national independence lie shattered. Hunger stalks the land; the factories stand idle; and the infrastructure, built at such enormous cost, disintegrates. Inevitably, social and political stability is undermined as past policy approaches are discredited and the search for more successful alternatives grows more urgent. Nowhere is this need for new perspectives and new hope more acute than in the area of industrialisation. The sector that was once widely regarded as the key to 'development', is now even more widely presented as the main villain of the piece; a bloated, overly protected parasite devouring the surpluses eked out of the soil by an oppressed peasantry and thereby actively destroying the very basis on which even its own continued growth depends. Furthermore, it is now widely held that the primary cause of this perverse and generalised outcome has been the myopic, venal and misguided behaviour of a self-seeking, urban African elite that has pursued its own short-term interests at the expense of both efficiency and welfare. The present crisis is thus seen as the cumulative result of countless industrial (and infrastructural) investment decisions, made with inadequate regard for their lively economic and financial rate of return' [World Bank 1984a:24].

This assessment of Africa's post-independence failure is rapidly assuming the status of 'received wisdom', if only by virtue of the fact that it is militantly asserted by those institutions that control the world's noncommercial financial flows. Thus, in the latest of a series of increasingly sophisticated reviews of Africa's problems, the World Bank suggests that this debate has reached the point where 'the emerging consensus on policy issues dwarfs any remaining areas of dissent' and that 'neither the essential objectives of Africa's development nor the policy issues that must be addressed to achieve them are in dispute, even though views on timing and priorities may differ'. Moreover, the conclusions thus reached are thought to be so clear and specific that 'action in the main areas of agreement will be enough to ensure economic progress' [World Bank 1984a:2-3]. Such optimism is certainly welcome. However, to judge whether it is also plausible requires an examination of the proposed policy changes and of the analysis on which they are based.

The issue is particularly important because access to international finance is to be made strictly conditional on acceptance of this 'consensus' and on the closely supervised implementation of its policy prescriptions. Reluctance to comply is to be overcome with a more effective combination of sticks and carrots. Since Africa's crushing debt burden is stick enough for the moment, the present emphasis is on better rewards for good behaviour, to encourage those who hesitate. Hence, while

there are definite signs of greater willingness of African governments to consider and undertake policy reforms, only a few ... are likely to be ready immediately. Donors should (therefore) . . . assure that adequate external support can be rapidly mobilised for additional countries when they embark on a major reform programme (and) a special facility might be established to maintain a reserve for this prupose [World Bank 1984b:19]

Of course governments need not only recognise the need for reforms' but must also see 'which direction to take', if they are to participate in 'the development of ... appropriate macroeconomic and sectoral policies' [World Bank 1984b:17]. The implementation of such 'appropriate' policies is to be systematically supported by a more coordinated aid effort, ensuring that all donors accept the same definition of 'appropriate' [World Bank 1984a:41ff]. For governments with the requisite 'political will' the issue thus becomes a largely technical one that can be substantially resolved if donor agencies 'help design national action programmes, and then, most importantly, provide

IDS Bullerin. 1985, vol 16 no 3. Institute of Development Studies. Sussex 
their aid within this framework' [World Bank 1984b:17].

\section{The Substance of the 'New Consensus'}

While it would certainly be encouraging and desirable if the policies needed to rescue Africa from its present plight were 'not in dispute', it would also be truly remarkable at a time when the economics profession is in disarray and disrepute and the global policy debate has become a cacophony of discord. It is not, therefore, surprising to find that the much vaunted consensus is only skin deep and that, apart from agreement on certain short term responses to the current crisis, it does not extend far beyond the platitude that Africa needs to achieve greater efficiency in its use of resources.

This is not to deny the importance of the increased consensus on short term measures, already discussed in the editorial of this Bulletin. It is certainly significant that the World Bank has now abandoned the extreme position developed in its Accelerated Development Report [World Bank 1982], which placed largely unqualified faith in the market's ability to rectify the problems of Africa. In its most recent review of this subject [World Bank 1984a] it has developed a more subtle and serious argument which explicitly recognises the importance of institutional and political factors and clearly acknowledges the virtual impossibility of significantly increasing African export earnings in the short term (see Martin Godfrey's article). This allows it to see clearly that any attempt to reverse Africa's present downward spiral will necessarily require a heavy injection of concessional, programme (nonproject) funding that will allow existing industrial and infrastructural facilities to be rescued from their current disastrous paralysis. At the same time, however, there has been far less convergence regarding the more general social and economic policy changes revealed as necessary by the events of the last 25 years. In effect, the urgent need for concessional funds is now agreed; the nature of the conditions that should be attached to these funds is not.

On the more general policy issues, the most recent Bank review remains firmly committed to the view that Africa should allow private enterprise and world market prices to play a much greater role in determining resource allocation. What has been revised, somewhat, is its judgement of the feasible and desirable speed of that adjustment and, rather less clearly, its view of the nature of the optimal socially and politically defined limits required to condition the operation of the 'free market'.

In a certain general sense these conclusions are virtually unassailable, especially so long as they remain as 'short on specifics' as they must inevitably be in a discussion of so numerous and heterogeneous a set of economies as those of sub-Saharan Africa (SSA). Certainly in such a context it would be foolish even to attempt to define a universally applicable 'optimal' balance between public and private sectors, or between competition and protection. Nevertheless, in spite of the great differences between SSA countries, in terms of size, resources and politics, their present position has some remarkably general features. Thus it is possible to agree that in most of SSA today the rationality of price signals has been substantially undermined; foreign exchange earnings are insufficient to meet debt repayments or to sustain economic growth; and agricultural sectors have generally been undermined by the needs of rapidly deteriorating nonagricultural sectors. These, however, are the symptoms and not the causes of Africa's malaise and there is little consensus regarding the mechanisms that have led to such a remarkably uniform outcome in such diverse settings, or on the policy changes needed to reverse past trends.

As regards these more general issues, the alleged new consensus appears to contain little that is new and nothing that could reasonably be regarded as a safeguard against a repeat of past 'mistakes'. Indeed, 'the new approach' is largely 'the old approach' dressed up in new rhetoric. It is not likely to exorcise the evil spirits that have bedevilled the region's development efforts for the simple reason that it has learned the wrong lessons from its recent past.

\section{It's not Always so Easy to be Wise After the Fact?}

The chief lesson that has apparently been learned by the international agencies is that 'the heart of Africa's economic crisis is the low rate of return on its capital investment' [World Bank 1984:41]. That, in turn, is largely said to be the result of 'inadequate discipline over the use of investment resources' resulting from the intrusion of domestic social and political pressures that fail to appreciate that 'changing the structure of an economy still requires strict adherence to criteria for project selection and design in order to maximise the return on investment' [World Bank 1984a:24]. Foreign donors (and investors?) are allocated a modest share of the blame, because they have been too lax and uncoordinated to ensure an 'adequate' regard for this need 'to maximise the return on investment'.

This position is developed from a perspective in which the market defines efficiency. Hence, its influence is assumed, by definition, to induce efficiency except where 'imperfections' require institutional intervention. This, in turn, has to be primarily designed to ensure that investment decisions are insulated from 
'distortions' stemming from 'unwarranted' domestic social or political pressures. The hope for the future lies in the fact that the international financial institutions are to coordinate and intensify their monitoring of Africa's economies, in order to ensure that efficiency, in this sense, is maximised.

The discussion of SSA's industrial experience clearly reflects this orientation. Between 1970 and 1984 SSA saw: an increase in its share of global manufacturing value added; a substantial rise in the proportion of its people employed in industry; and a decline in its share of global manufactured exports, which fell from a tiny share $(0.47$ per cent $)$ to a negligible one $(0.24$ per cent $)$. The juxtaposition of these trends is said to illustrate the growth of an inefficient, uncompetitive sector that 'becomes a burden on the more efficient and dynamic parts of the economy' [World Bank 1984a:36] especially through its high net import costs that contribute to the acute foreign exchange shortage that now throttles growth and devastates productivity levels. As a result one can agree that today a high proportion of SSA's industry is: relatively uncompetitive and dependent on high protective barriers; too net import intensive; and paying wages and salaries not justified at present productivity levels (a corollary of its relative inefficiency). However, agreement on the reasons for this outcome is nothing like as widespread as those emphasising the 'new consensus' appear to think.

Even without a detailed discussion of Africa's industrialisation, [World Bank 1984a] Toward Sustained Development concludes confidently that, in this sphere too, the basic problem was a failure to allow market forces to exert more influence over resource allocation. Moreover, in spite to its frequent references to various institutional issues, its discussion remains firmly rooted in the imaginary, equilibrium world of neoclassical economics, as indicated by its frequent implicit use of concepts like 'equilibrium exchange rates' and 'undistorted market prices'. Thus, Africa's industrial problems are summarised in the following terms:

Outside agriculture, price distortions have been reduced in recent years... However, the distortions resulting from price controls and relatively high levels of industrial protection remain severe in most of sub-Saharan Africa. Many of the most wasteful investments have been oriented toward sluggish (or declining) and heavily protected internal markets. Those that have been export oriented have often been made unsuccessful by overvalued exchange rates. In a period of structural adjustment, those that have no future, even in an environment of improved foreign exchange availability and other incentives, should be the first to go ... greater regional integration will follow from more open trade and currency arrangements ... (while) flexible exchange rates will frequently be necessary to stimulate more open trade and currency arrangements

[World Bank 1984a:36-7]

This conveys a clear message. Even in Africa today, market forces operating through 'more open trade and currency arrangements' and through 'flexible exchange rates' will play a crucial role in rectifying the errors of the past by eliminating 'lame ducks' and increasing efficiency. Even the problem of regional integration will become less intractable once market forces are thus released. Evidently, the possibility that many of the wasteful economic activities now in existence might actually be primarily the result of market pressures is simply ruled out by the assumption that market pressures induce efficiency.

True as this may be under certain circumstances, it is hardly the whole story. However, the Report barely acknowledges that: competitive pressures can and do destroy businesses and people; the 'equilibrium exchange rate' may involve wage rates and income levels below subsistence; the 'real' international market may saddle weaker protagonists with more than their share of unemployment, destitution or starvation; more open markets can increase uncertainty and transmit costly, economically unjustifiable and politically manipulated 'market signals' (such as today's extortionate international interest rates) or drive hard pressed economies into disastrous competition, 'over-producing' a restricted range of commodities. While these problems are not inevitable, they surely deserve to be taken seriously in Africa today.

Equally problematic is the Report's failure to examine the possible link between 'more open markets' and the politics of industrial (and general economic) policy, apart from the passing remark that in countries that encouraged private enterprise, governments gave businesses too much protection' [World Bank 1984a:25]. Apparently the authors are not disposed to enquire why this should have been such a common experience. Similarly, the Report repeatedly recognises the crucial need for clear strategic choices made from a national perspective if one is ever to overcome the problem that 'projects have not always been consistent with the priorities necessary for achieving national development objectives' [World Bank 1984a:41] or if one is to reconcile the 'static efficiency' of the short and medium term with the rationality defined by society's long term objectives [World Bank 1984a:4, $24,37,41,42,45,47]$. Unfortunately, apart from deploring SSA's 'lack of a tradition of national political organisation' [World Bank 1984a:25] this too 
is treated as an 'exogenous' problem, unrelated to the economic policy issues at the centre of the discussion.

\section{Drawing General Lessons from a General Experience}

It is more than a little ironic that in the 1980s the discussion of SSA's experience should witness this reassertation of the belief in a benign and manageable market. It is even more ironic that this region's experience is apparently held to undermine the arguments of those liberals and radicals loosely grouped under the dependency label, since from the outset their central concern was the danger that market induced, 'neo-colonial' patterns of development would often prove disastrous in the weaker developing countries. In fact, Africa's present crisis powerfully illustrates the legitimacy of their fears. As is well known this school feared that the 'neocolonial' patterns of development would lead to: excessive import dependence; an anti-peasant and anti-food bias; an unmanageable debt burden; deteriorating terms of trade; divisive and ultimately unsustainable consumption patterns; an erosion of the ability to formulate or implement nationally defined strategies; and a degree of political polarisation and militarisation that would allow the eventual crises to be met by virtually unlimited repression, supported by international capital, anxious to ensure that, whatever the domestic circumstances, priority should be given to debt repayment. In this view, domestic circumstances simply have to adjust to 'the facts of economic life' created in the meantime by these development patterns. From this perspective the 'new orthodoxy' simply appears as the rationalisation of the last desperate stage in that process.

This does not imply that those who feared and anticipated the present outcome were able to propose (or implement) effective alternative policies, since clearly they were not. It does mean, however, that Africa's recent experience should increase our interest in those analytic perspectives, especially since many of those now espousing the 'new orthodoxy' had long denigrated such fears, arguing that: concerns about consumption patterns represented a misplaced egalitarianism, as Africa's 'modernising elites' were the only conceivable source of the expertise and savings required for 'development'; that there was little danger in a heavy reliance on primary exports, whose terms of trade were not likely to fall; and that this base could safely be supplemented by as much capital as one could attract to expand industry and services for 'job creation'. Concerns about debt burdens were generally met by reminders that in a growing world, growing debts were only natural.
Given the fact that SSA's current problems stretch across the ideological spectrum one suspects that the present consensus should be to acknowledge that history has clearly borne out the fears of the dependency school in the case of the world's weakest economies. But that it has also shown the problem of averting those outcomes to be more intractable than had been imagined. This consensus could also include agreement on a series of important priorities, as is strikingly illustrated by the fact that most of the essential priorities identified by Toward Sustained Development could be found more eloquently stated in Nyerere's central policy documents arguing the case for Tanzania's 'alternative' policy in 1967 [Nyerere 1968]. These also called for a heavy emphasis on agriculture; emphasised the importance of food security; deplored inappropriate consumption patterns and excessive urban incomes; called for greater concern with small-scale production and more indigenous, less import intensive technologies; sought foreign capital inflows, compatible with 'national development objectives'; and urged a shift to more appropriate education.

Here the scope for consensus ends, however. The 'new orthodoxy', having belatedly come to espouse this position, dismisses the idea that present problems may be largely a result of the pressures exerted on SSA's relatively weak economies by the 'imperfect markets' of the neocolonial world. Instead it asserts that they are the result of excessive intervention in the market by exonegously determined 'political' forces that primarily reflect the short-sighted greed of a self-serving, bureaucratic, urban elite, which is presumably the former 'modernising elite', unaccountably 'gone bad'. The international agencies are bravely asked to shoulder a small part of the blame, but only for not being firm enough with their unruly wards. By this means, Africa's crisis is presented as just as much proof of the beneficent efficiency of the market, as the success of the mythical 'laissez-faire South Korea' and now, in Toward Sustained Development, also the experience of the equally mythical 'open economy of India'. ' One can admire the flexibility of the paradigm and the perseverance of the protagonists, but one cannot defend the argument or its conclusions; nor

\footnotetext{
The use of India in Toward Sustained Development to illustrate the benefits of a 'market oriented' policy is quite remarkable. Until late into the 1970 s India was considered a major problem because of its excessively nationalist policy, especially as regards food and industry. Indeed I recall arguing at a conference in 1977 that, if the more pessimistic prognoses of the world economy were accurate, then the longer term strength of the Indian pattern might well make it into the "success story" of the 1980s, displacing Brazil's more ephemeral and riskier gains. Of course. as a more 'nationalist' approach gains in relative strength it can afford to become more open and will also attract more capital. though on its own terms. At this point the symptoms can be presented as causes in order for yet another 'miracle' to be revealed, confirming the faith in economic jiberalisation.
} 
can one realistically hope that the policy perspectives thus derived will bring much relief to the people of Africa.

Having thus reaffirmed the market's virtues, it is not surprising to find the 'new consensus' proposing a largely unchanged policy perspective, dressed up in a new rhetoric and ostensibly differentiated from its earlier version by certain changes in emphasis. What remains unchanged is the message that the African countries should: encourage the international market to determine patterns of resource allocation; emphasise strongly the provision of incentives to foreign capital to create jobs; rely heavily on external experts to ensure 'efficient' project selection; and accept agricultural exports as the basic engine of growth, while relying both on rapid increases in total agricultural output and on food imports to meet food requirements. These are surely the very same principles that have guided most of SSA's postcolonial governments and the public and private agencies providing their foreign finance. Why then should one expect different results in future?

The authors of Toward Sustained Development would presumably disagree with this formulation, arguing that, although lip-service may have been paid to these principles, they were largely ignored in practice. This, in spite of the fact that they would accept that in SSA virtually every project of any size has been vetted by external 'experts' applying general commercial principles, so much so that the Report itself concludes that in many African countries, the pattern of development spending has become increasingly determined by the aggregation of aid programmes' [World Bank 1984a:4]. Even so, they would argue that in future things would be different if their Report were accepted and implemented, because then these same principles would actually be applied more rigorously, under the watchful eye of the better coordinated and more activist financial agencies that are proposed. Unfortunately, however, these conclusions are unconvincing, because they misrepresent both the technical and the political causes of the presently observed 'excessive divergence' from 'undistorted market prices'.

In practice, as Toward Sustained Development acknowledges, adherence to commercial principles can never actually determine policy since it always leaves large areas of uncertainty, including: the need to judge the present and future strengths and weaknesses of markets and institutions; the need to define 'social time preference' and national development objectives; and the need to choose between the relative risks of alternative strategies. These factors define legitimate and important areas of uncertainty in which the application of static efficiency criteria is quite inapproriate and this will be as true in future as it has been in the past. Hence, a substantial divergence from 'undistorted' market prices will continue to be 'justified' even on narrow economic grounds, and the optimal degree of that divergence will continue to be unknown. Toward Sustained Development acknowledges this scope for 'genuine mistakes and misfortunes' but asserts that these 'cannot explain the excessive number of 'white elephants' in SSA [World Bank 1984a:24]. This may be so, but one suspects that, at a time when bankruptcies in much stronger economies are at record levels due to the radical changes that have occurred in international prices, markets and interest rates, a rather large proportion of these 'white elephants' would qualify as genuine 'mistakes and misfortunes'. For some reason the Report hardly addresses the question of how exposure to this risk might be reduced in future, especially in the case of those economies that are so weak that they could not respond dynamically to an increase in international competitive pressures.

Three factors determine this risk: the degree of instability and uncertainty in the international economy; the directness of an economy's exposure to such external fluctuations; and the degree of optimism embodied in the critical judgements that always have to be made in defining strategies or selecting projects. The first two of these clearly suggest the need for particular care in 'opening up' relatively weak economies, especially when international economic instability is likely to be a major problem; the third raises further important issues that have also been largely ignored in Toward Sustained Development. These will be considered in the context of a discussion of that other type of 'market distortion': that is not economically justifiable; that is usually deemed to be politically induced; and that is accorded such great significance by the Report.

It has been shown that this Report holds the African elites primarily responsible for Africa's present plight because they are deemed to have put their short-term, sectional self-interest before their own and the nation's longer term interests, partly out of ignorance and partly out of weakness. This problem is now to be rectified because their ignorance is to be cured by the 'realisation' that it was their failure to heed commercial principles more directly that lies at the heart of the current crisis. At the same time, their weakness in the face of internal political pressures, generally portrayed as illegitimate sectional demands, is to be cured by adding a bigger carrot (the highly conditional 'special facility') to existing sticks (the debt itself, aid to enforce 'law and order', exclusion from normal IMF facilities, toleration or support of violent subversion). Their backbones thus strengthened and their thinking clarified by a larger, more 
coordinated input of external expertise, Africa's elites are once again to become the spearheads of development. No mention is made of the possibility that harrassed officials desperately trying to attract foreign capital to ailing and weak economies beset by urgent social and political problems, will once again find themselves with little bargaining power vis-à-vis those providing the capital. The existence of this pressure is, after all, the reason why the Report repeatedly acknowledges that 'donors must take some responsibility (for the current difficulties): the pressures they put on governments, the inappropriate design and selection of their products, and the lack of coordination among themselves - have all contributed to the low rates of return on investment', though one wonders what benefit would have been derived if agencies, selecting and designing projects 'inappropriately', had coordinated their efforts better. Surely, the fact that levels of protection are generally so high in SSA has a lot to do with the great influence exerted under such conditions by the foreign investor, and here the private investor is at least as 'guilty' as the much pilloried aid agency.

The most extraordinary aspect of the discussion in Toward Sustained Development is that, in spite of its clear interest in the problems created by conflicting sectional interests, it fails even to consider the possibility that 'external financial agencies' might represent interests that could conflict with those 'national development objectives' that it rightly identifies as vitally important. Indeed, this presumed neutrality of international agency 'expertise', or of foreign investment, is a vital feature of its discussion and one that effectively obscures yet another critically important issue from view.

In fact it is surely obvious that aid donors and foreign investors do have interests that systematically guide their behaviour; and that chief among these is the desire to sell goods or services (machinery, projects) or extend loans and then to ensure that payment for such transactions will be effected promptly and in hard currency. Furthermore, since investors have managed to spread the responsibility for honouring the consequent commitments across society as a whole through government loan guarantees, they now have every inducement to push projects and loans systematically beyond commercially, economically or socially prudent limits, since the cost of project failure will not be borne by them, but by the recipient national economies. This surely was an important reason why donors and contractors continued to push new projects even when the economic prospects of most African countries were clearly, decidedly bleak. ${ }^{2}$ Governments, always under pressure to achieve higher growth and operating under a severe foreign exchange constraint, naturally find it almost impossible to refuse such funds, especially since they always come along with commercial feasibility studies showing them to be viable and desirable.

This effectively represents a powerful and systematic source of pressure inducing excessively optimistic assumptions to be made in the process of project and programme selection, and the Bank's latest proposals would possibly even strengthen the mechanisms that produce this result. So long as these pressures remain undiminished, investment will continue to be pushed to high risk levels, with the result that Africa will continue to teeter on the edge of economic disaster, heavily exposed to unforseen reverses such as those it has recently suffered; always being pushed beyond its borrowing capacity and hence, continually forced to demand greater efficiency and more sacrifice of its people in order to meet the obligations thus assumed. Under these circumstances, some modest increase in the efficiency of resource use would do little to alter SSA's basic position. Indeed, at present, any such 'success' would largely serve to further depress many of its export prices and reduce the already limited willingness of creditors to ease its accumulated debt burden. In this context it may be noteworthy that, in spite of its candour in acknowledging the role played by 'exernal agencies' in pushing unwise and unjustified projects into SSA, Toward Sustained Development never draws the logical conclusion that a belief in market principles might suggest, namely that the debts thus incurred should be written off, as unwise investors paid the price of their folly.

In industrial policy terms this means that there will continue to be powerful pressures inducing projects to be technically justified by 'optimistic' judgements concerning the crucial imponderables on which every project evaluation hinges. It is likely that this was the main reason for the so-called 'inadequate regard for' the rate of return on projects, shown by foreign investors and donors and deplored by the Report.

\footnotetext{
Those who have been involved in the process of project and programme selection in countries like Tanzania will know only too well the constant frustration of 'winning the argument' for some programme that has low import intensity, high participation. low capital intensity and strong multipliers. because it diffuses income widely, only to find that the 'decision' goes a different way because some immediately more attractive, more capital intensive alternative has emerged. The latter will be backed by finance from abroad; shown to be 'feasible' by some technocratic document prepared by 'experts' and comprehensible to very few: and will undoubtedly help to achieve more growth in the short term. These are not isolated cases. They are endemic. and they arise because the external pressures that sell or lend by 'fomenting optimism' readily find local partners hoping to share in the consequent benefits. The present attempt to blame these factors on the aid agencies alone is completely wrong. Commercial donors and the more commercially oriented agencies aresystematically the worst offenders. Indeed. the only donors who sometimes take a longer view and support lower risk options are the agencies that are not dominated by these principles.
} 
However, the Report's new proposals change nothing in this regard, except for a few marginal adjustments related to the current crisis. It is these adjustments that are used to suggest that this Report contains something that is substantially different from the practices of the now discredited 'development economists', who had, after all, been in the business of applying commercial criteria to the real world. Thus, it is suggested that the future application of commercial principles will reduce protection, encourage the expansion of efficient export production and support programme, as against project, lending. However, these differences amount to very little in fact. The first two simply amount to making extremely optimistic assumptions as to what is possible in SSA in the short or medium term and as to what scope there is for resisting the demands of investors demanding continued protection. The new willingness to support programme aid is significant, but is clearly a specific response to the immediate fear that the ability to repay past debt obligations may now be in jeopardy. Indeed, it is difficult to avoid the conclusion that this is the main reason for the urgent tone of the present discussion; after all, possibly the biggest change implied by the new proposals is the further insulation of the decision making process from those domestic social and political pressures that might otherwise divert attention from the primary need to 'maximise economic and financial returns'.

When all is said and done, if the Bank's proposals are accepted, the same suppliers and donors, using the same techniques and principles and under the same (or greater) pressures to sell (or 'recycle') will continue to dominate the process of project selection, and in the process effectively preempt choices about development priorities. To be sure, projections will be a little more cautious for a brief period, until repayment of existing obligations has been assured, but they clearly stand poised to take up any slack that may appear. For the African masses there will be little respite. They will continue to be bombarded with endless appeals for that little additional increase in efficiency or reduction in costs, that will allow yesterday's obligations to be met.

The cruel fact is that when things get difficult economically, as they did after the early 1970s, the weak do most of the suffering as the strong use their strength to secure their position. It seems slightly obscene to tell Africa to 'pull itself together and become more efficient' when it has had the rug pulled out from under its feet by the harsh and unjustified policies of the main industrial nations, which have added a crushing interest rate subsidy to the richest people in the richest nations, to the heavy burdens already imposed on Africa by changes in commodity prices, markets and climatic patterns. Under these circumstances it is far from clear on what basis it is asserted that internal policy failures are the root cause of Africa's current problems and even less clear why policies that largely confirm and strengthen past patterns of investment and of project selection could be expected to reverse past trends.

\section{Politics: the Neglected Dimension}

What then are the implications for Africa and especially for its long term aim to industrialise? The central point is simple enough. If Africa is to develop its productive forces to benefit its people then it must develop the capacity to manage its integration with the international economy in a manner that allows benefits to be weighed against the attendant risks. Furthermore, in assessing these risks it should be recognised that the international market is an arena of struggle in which political and economic dimensions are inextricably intertwined, and in which the more powerful are able to turn many things to their advantage. Certainly it would be wrong to assume that the international financial institutions represent no particular interests or that their 'neutral' expertise could play a central role in building up a nation's capacity to define its 'national development objectives' within that context. The task is precisely for each nation (or group of nations) to define its (their) interests in relation to those of other national and international interests. In this regard, it is one of the most difficult tasks to develop an ability to say 'No!' to someone offering finance for a project that he claims to have shown to be viable.

The latest Bank Report recognises the central importance of this point, when it repeatedly states that the expertise of the agencies must be applied within a clearly defined framework that reflects 'national development objectives'. The question is: 'how does one achieve the capacity to accomplish that prior task?' More to the point, is there not a real danger that the 'premature' liberalisation of an economy could undermine or destroy all hope of developing those critical capacities? Certainly, without the ability to define and to manage their 'constructive isolation' from the external world, the African economies will continue to be cast in the role of the remote periphery that carries more than its fair share of global unemployment and of the costs of global disequilibrium. For many African countries today, an 'equilibrium exchange rate' would be one at which many people' incomes would lie well below the level needed even for survival.

For Africa, the lesson of the past 25 years is not that it has not integrated itself sufficiently into the international market. It is rather the opposite: that it has integrated to a degree, and in a manner, that has 


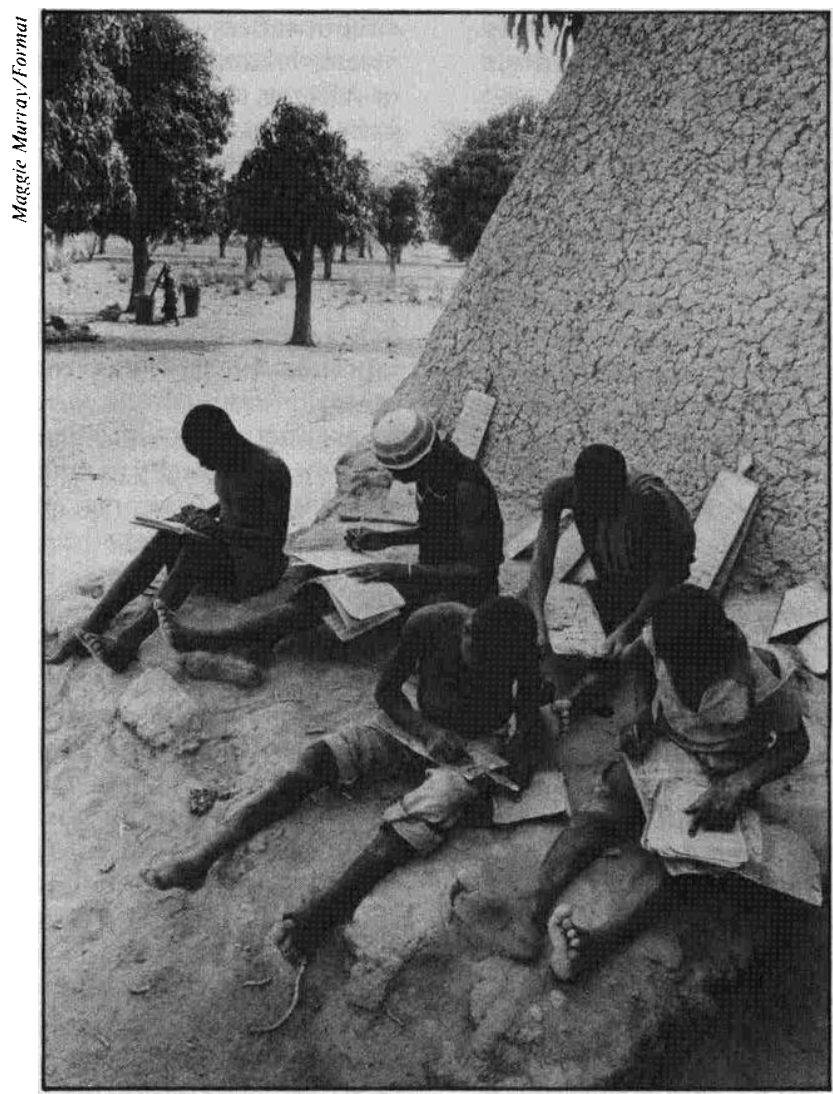

The development of human resources demands political choices.

simply proven unmanageable. It is now easy for any old bank to see that a more cautious approach to investment is needed, one that maintains a closer link between agricultural and industrial incomes and that contrains the growth of import intensive consumption and production patterns. The difficult question is: how does one create the degree of unity and of cohesion that allows such a 'slow but steady' approach to be applied, when powerful external pressures reinforce domestic pressures from elites demanding modern life-styles today; a general impatience for material improvement; and a natural tendency to make optimistic assumptions in a world where these yield loans that purchase real goods? The most difficult task is to build and maintain a domestic coalition that would accept and support a policy that settled for slower but steadier growth at lower risk, but that could also ensure that the implied reduction of external competitive pressures did not lead to stagnation? That is the objective, and the task is to find measures that will make its realisation easier in more countries.
The policies now being forced upon Africa will not cont ribute to that objective, any more than they have contributed to it in Jamaica, Guatemala or Chile. They will rather polarise and destabilise an already difficult situation and they will lead to efficiency only in the narrowest and least socially defensible sense.

The challenge is to offer assistance in a form and 'on conditions' that will help the African states to define and to implement such 'low risk strategies', more directly concerned with domestic welfare and security and proceeding in a context where 'success' is defined on the basis of a steady improvement in efficiency over time, irrespective of whether this matches the cost reductions achieved in South Africa's labour camps. Suggestions that if the Africans just tried a little harder, with help from the agencies, they could meet present external challenges head on, are merely recipes for the disasters of the future.

Unfortunately the experience of countries like Tanzania and Guinea reminds us that this objective is 
not attainable merely, because the need for an alternative is recognised by those in power. However, neither is it attainable through the international agencies, even if they are temporarily converted to a more cautious and more helpful view, a conversion likely to last roughly as long as the possibility of debt repayment is under threat. Nor, finally, is it attainable merely as the automatic outcome of neocolonial development patterns, as is apparently believed by some theorists following in Bill Warren's footsteps, who simply assume this transition, at the same time as castigating various straw men who allegedly do not take the political dimension of this problem seriously and who are said to believe that closing an economy will necessarily lead to socialism [Sender and Smith 1984]. Maybe this group's total rejection of all aspects of the dependency debate would be modified if they realised that that debate had actually addressed that very question, namely: how does an economy achieve the capacity to impose its own social and political constraints on the operation of the market.

There is surely no formula that will solve SSA's problem 'in general', but at least four things are undoubtedly required if success is to become a possibility. First, there has to be an economic structure that gives significant power to the mass of a nation's population and their representatives. Second, the longer term risks associated with an economy's external links have to be clearly recognised and managed in the light of the knowledge that if these move out of balance they can and will present any society with totally unmanageable problems. Third, the developed nations have to be induced, at least to tolerate the adoption of such low risk domestic policies, even when these do not coincide with the interests of international capital. Fourth, there must be a major remission of SSA's current debts since, otherwise, any improvement that is achieved in a desperately difficult situation will simply accrue to Africa's vigilant and insatible creditors. In relation to these tasks it has to be said that in spite of its advance over previous Bank reviews of Africa's problems, the proposals contained in Toward Sustained Development are wholly inadequate and still divert attention to issues that, by themselves, cannot begin to solve the problem. Indeed, seen from this perspective, the main effect of those proposals would merely be the perpetuation of old patterns. In that context, the main thrust of the argument appears to be mainly to explain why the destitute and starving people of Africa should accept the payment of extortionate interest rates to overfed and wealthy people, as an overriding economic priority. It would be sad indeed if this view commanded a consensus. Fortunately it does not.

\section{References}

Nyerere, J. K., 1968, Ujamaa: Essays on Socialism, Oxford University Press

Sender, J. and S. Smith, 1984, 'What's right with the Berg Report and what's left of its Critics?', Discussion Paper 192, IDS, Sussex

World Bank, 1982, Accelerated Development in sub-Saharan Africa: an Agenda for Action, Washington DC

-1984a, Toward Sustained Development in sub-Saharan Africa: a joint Programme of Action, Washington DC

-1984b, 'Revised President's Report to the Development Committee on Current Development Issues', R84-225/1, September 10, 1984 (mimeo) 